\title{
The Dublin Statement on Water and Sustainable Development
}

Scarcity and misuse of fresh water pose a serious and growing threat to sustainable development and protection of the environment. Human health and welfare, food security, industrial development, and the ecosystems on which they depend, are all at risk, unless water and land resources are managed more effectively in the present decade and beyond than they have been in the past.

Five hundred participants, including governmentdesignated experts from a hundred countries and representatives of eighty international, intergovernmental, and nongovernmental, organizations attended the International Conference on Water and the Environment (ICWE) in Dublin, Ireland, during 26-31 January 1992. The experts saw the emerging global water-resources picture as critical. At its closing session, the Conference adopted the Dublin Statement of which this is the Preamble and the Conference Report. The problems highlighted are not speculative in nature; nor are they likely to affect our planet only in the distant future. They are here and they affect all humanity and Nature now. The future survival of many millions of people demands immediate and effective action.

The Conference participants call for fundamental new approaches to the assessment, development, and management, of freshwater resources, which can only be brought about through political commitment and involvement from the highest levels of government to the smallest communities. Commitment will need to be backed by substantial and immediate investments, public awareness campaigns, legislative and institutional changes, technology development, and capacity building programmes. Underlying all these must be a greater recognition of the interdependence of all peoples, and of their place in the natural world.

In commending this Dublin Statement to the world leaders assembled at the United Nations Conference on Environment and Development (UNCED) held in Rio de Janeiro in June 1992, the Conference participants urged all governments to study carefully the specific activities and means of implementation recommended in the Conference Report, and to translate those recommendations into urgent-action programmes for Water and Sustainable Development. To obtain copies of the full statement and Conference report, please contact the undersigned.

\author{
EIRAH GorRE-DALE \\ ICWE Secretariat \\ c/o World Meteorological Organization \\ Avenue Giuseppe-Motta 41 \\ 1211 Geneva 20 \\ Switzerland.
}

\section{Aquatic Conservation Network Formed to Help Save Endangered Aquatic Life}

The Aquatic Conservation Network (ACN) is a new, non-profit organization which has been established in response to growing pressures on the aquatic environment. It provides a unique linkage between amateur and professional initiatives in aquatic conservation, and promotes the development of new programmes in conservation and captive breeding which foster amateur participation under the guidance and endorsement of the scientific community. Initiated by North American aquarists who are 'Dedicated to the Preservation of Aquatic Life', it is planned to fill the need of a world-wide body with such an aim.

As part of its efforts for improved communication between amateur and professional aquarist activities, the ACN has launched a quarterly bulletin 'Aquatic Survival', which will provide a means for the exchange of information pertaining to threatened aquatic organisms and their habitats, both freshwater and marine. The first issue was released in March 1992, and others will follow at approximately 3-monthly intervals henceforth.

A longer-term goal of ACN is to develop new programmes which foster appropriate participation by ama- teur aquarists in captive breeding and in conservation projects in the field. A Steering Committee, with representation from the scientific community, aquarist organizations, and industry, has been established to ensure that programmes are developed which adhere to sound scientific principles. Initially, these programmes will concentrate on issues concerning threatened and endangered freshwater fish species.

A membership in the Aquatic Conservation Network will help to ensure that important work towards aquatic species and ecosystem survival will be carried out. The basic membership fee is only $\$ 25$ (Canadian or US currency) but other, more supportive categories are planned. Anyone interested in becoming a member, or in volunteering to become involved in the activities of $\mathrm{ACN}$, should write to the undersigned.

ROBERT V. HUNTLEY, Director
Aquatic Conservation Network
540 Roosevelt Avenue
Ottawa
Ontario K2A $1 Z 8$
Canada.

\section{Global Environmental Movement Organization (GEMO)}

\section{Preamble}

Today the whole world's attention is apt to be fixed on solving pollution and other environmental problems which constitute a huge challenge. Towards such solution it is impossible to get far unless each and every person realizes his or her part and becomes involved so as to contribute, individually and collectively, to the ever-increasing need of protection from environmental pollution. As this is the problem of every nation in the world, Nepal does not escape from it.

It is plainly obvious that, due to its often drastic landscape, pressures of population density, and lack of public awareness, Nepal's environmental problems are serious. The solution of these problems is scarcely possible from the Government level alone, and so the nongovernmental 